See Article page $\mathrm{XXX}$.

\section{Commentary: Just do it: Complete coronary artery revascularization-more is less!}

\author{
Federico Milla, MD, and Vinod H. Thourani, MD
}

In this edition of the Journal, Bianco and colleagues ${ }^{2}$ reported their experience with 3356 patients undergoing first-time isolated coronary artery bypass grafting, with a total of 889 patients undergoing incomplete revascularization and 2467 complete revascularization. A unique aspect to this study is that the authors defined stenotic vessels as both branched and nonbranched vessels that had $\geq 70 \%$ stenosis or $\geq 50 \%$ left main stenosis by angiography. The groups were analyzed by 2 different methods, including any coronary vessel with significant stenosis and main-branched vessels with significant stenosis. Advanced statistical methods to account for risk adjustment with inverse probability treatment weighting were used, demonstrating improved both 1-year $(94.6 \%$ vs $92.5 \%)$ and 5-year $(86.5 \%$ vs $82.1 \%)$ survival. In addition, freedom from major adverse cardiac and cerebrovascular events (MACCE) was also significantly better for the completely revascularized cohort. Incomplete revascularization of main branch vessels was associated with increased mortality and MACCE, whereas those with incomplete revascularization of nonmain branch vessels were not statistically associated with a difference in survival or MACCE. Midterm survival, MACCE, readmissions, and repeat revascularization were all improved with complete revascularization across the entire group.

While most studies on this subject appear to agree on MACCE reduction with complete revascularization (however defined), statistically significant reductions in

\footnotetext{
From the Department of Cardiovascular Surgery, Marcus Valve Center, Piedmont Heart Institute, Atlanta, Ga.

Disclosures: The authors reported no conflicts of interest.

The Journal policy requires editors and reviewers to disclose conflicts of interest and to decline handling or reviewing manuscripts for which they may have a conflict of interest. The editors and reviewers of this article have no conflicts of interest.

Received for publication June 20, 2021; revisions received June 20, 2021; accepted for publication June 21, 2021.

Address for reprints: Vinod H. Thourani, MD, Department of Cardiovascular Surgery, Marcus Valve Center, Piedmont Heart Institute, 95 Collier Rd, Suite 5015, Atlanta, GA 30308 (E-mail: vinod.thourani@piedmont.org).

J Thorac Cardiovasc Surg 2021; $\mathbf{\square}: 1-2$

$0022-5223 / \$ 36.00$

Copyright (c) 2021 by The American Association for Thoracic Surgery

https://doi.org/10.1016/j.jtcvs.2021.06.031
}

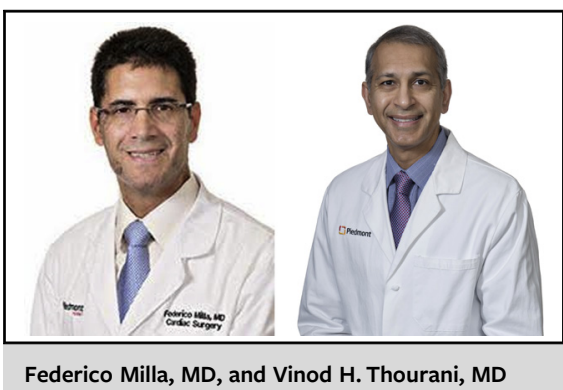

CENTRAL MESSAGE

Incomplete revascularization of main branch vessels was associated with increased mortality and MACCE.'

mortality have not been unanimous as would be expected, highlighting the complexity and limitations of retrospective studies. ${ }^{1,3,4}$ In addition, a unanimous definition of complete and incomplete revascularization has not been consistent among retrospective studies. The current study was able to analyze the difference between revascularization of main branched vessels (left main, left anterior descending, circumflex, and right coronary artery) and nonmain branched vessels, such as diagonals and marginal vessels from both right and left territories. This does add significantly to the literature and remains important.

While it seems intuitive that complete revascularization leads to better outcomes, reasons for incomplete revascularization were not defined in the current study. Patient morbidities, risk scores, age, ejection fraction, conduit availability, experience of the surgeon, use of off-pump coronary artery bypass grafting, size and quality of target vessels, and perhaps time of the day, call schedule, and day of the week may have impacted the surgeon's decision on which vessels to bypass. It seems instinctual that most surgeons would not skip those vessels that are bypassable. However, there are scenarios in which the main coronary artery is not bypassable secondary to severe calcification or for other reasons. In those instances, we would strongly urge consideration should be given to coronary percutaneous intervention before discharge of that specific vessel. This hybrid approach may decrease MACCE and the consequences of unrevascularized myocardium.

In conclusion, the current study offers more evidence that revascularizing main branch vessels does have a significant impact: more main vessels bypassed leads to less morbidity and mortality. Although nonmain branched vessels do not 
lead to a survival benefit, it is plausible that bypass of some of these vessels will lead to improvement in chest pain or quality of life. While the current study did not evaluate the Canadian Cardiovascular Society Angina postoperatively, this remains a viable future research endeavor.

\section{References}

1. Hattler B, Grover FL, Wagner T, Hawkins RB, Quin JA, Collins JF, et al. Incidence and prognostic impact of incomplete revascularization documented by coronary angiography 1 year after coronary artery bypass grafting. Am J Cardiol. 2020; 131:7-11.
2. Bianco V, Kilic A, Aranda-Michel E, Serna-Gallegos D, Ferdinand F, DunnLewis $\mathrm{C}$, et al. Complete revascularization during coronary artery bypass grafting is associated with reduced major adverse events. J Thorac Cardiovasc Surg. June 9, 2021 [Epub ahead of print].

3. Garcia S, Sandoval Y, Roukoz H, Adabag S, Canoniero M, Yannopoulos D, et al. Outcomes after complete versus incomplete revacularization in patient with multivessel coronary artery disease: a meta-analysis of 89,883 patients enrolled in randomized clinical trials and observational studies. J Am Coll Cardiol. 2013;62: 1421-31.

4. Sandoval Y, Brilakis ES, Canoniero M, Yannopoulos D, Garcia S. Complete versus incomplete coronary revascularization in patient with multivessel coronary artery disease. Curr Treat Options Cardiovasc Med. 2015;17: 366. 